OPEN ACCESS

Edited by:

Xiaohu Dong,

China University of Petroleum, China

Reviewed by:

Weiqi Fu,

China University of Mining and

Technology, China

Jinghong $\mathrm{Hu}$,

China University of Geosciences,

China

Lie Kong,

Monash University, Australia

*Correspondence:

Liang Huang

huangliang@cdut.edu.cn

Specialty section:

This article was submitted to

Economic Geology,

a section of the journal

Frontiers in Earth Science

Received: 30 August 2021 Accepted: 23 September 2021

Published: 07 October 2021

Citation:

Zhang R, Gu S, Huang L, Zeng D, Li T and Zhang G (2021) Experimental Study on the Elemental Sulfur Solubility in Sour Gas Mixtures.

Front. Earth Sci. 9:767015 doi: 10.3389/feart.2021.767015

\section{Experimental Study on the Elemental Sulfur Solubility in Sour Gas Mixtures}

\author{
Rui Zhang ${ }^{1,2}$, Shaohua $\mathrm{Gu}^{1,2}$, Liang Huang ${ }^{1,3 *}$, Daqian Zeng ${ }^{1,2}$, Tong $\mathrm{Li}^{2,4}$ and \\ Guangdong Zhang ${ }^{5}$
}

${ }^{1}$ State Key Laboratory of Shale Oil and Gas Enrichment Mechanisms and Effective Development, Beijing, China, ${ }^{2}$ SINOPEC Petroleum Exploration and Production Research Institute, Beijing, China, ${ }^{3}$ College of Energy, Chengdu University of Technology, Chengdu, China, ${ }^{4}$ School of Earth and Space Science, Peking University, Beijing, China, ${ }^{5}$ Department of Petroleum Engineering, Southwest Petroleum University, Chengdu, China

The investigation of elemental sulfur solubility plays critical roles on sour gas reservoir development. In this paper, the solubility of elemental sulfur was directly measured by static method with gas samples from well $\mathrm{M} 1$ of a sour gas reservoir in Sichuan Basin. The results show that the solubility of elemental sulfur ranges from $0.001 \mathrm{~g} / \mathrm{cm}^{3}$ to $0.968 \mathrm{~g} / \mathrm{cm}^{3}$ at 40-98.9 MPa and 15-49.8 MPa. The elemental sulfur solubility increases with increasing temperature and pressure, especially when the pressure is greater than $30 \mathrm{MPa}$. Moreover, the $\mathrm{H}_{2} \mathrm{~S}$ content in sour gas mixtures is also an important factor affecting elemental sulfur solubility. The elemental sulfur solubility increases with increasing $\mathrm{H}_{2} \mathrm{~S}$ content of the sour gas mixtures. The experimental data in this paper display a consistent trend with the reported experimental data. Based on the experimental results, the chrastiltype model, Robert's model and Hu's model were investigated and compared. The results show that the chrastil-type model by fitting experimental data in this paper has less error and higher accuracy in calculating elemental sulfur solubility in $\mathrm{M}$ gas reservoir. The chrastiltype models proposed in the literature, meanwhile, are only based on the regression of specific gas components and experimental conditions, which lead to a large error in the calculation of elemental sulfur solubility of sour gas samples in this research. The research results provide important basic data and technical support for the development of $\mathrm{M}$ gas reservoir.

Keywords: elemental sulfur, solubility, sour gas, $\mathrm{H}_{2} \mathrm{~S}$ content, chrastil model

\section{INTRODUCTION}

Natural gas reservoirs with high sulfur content have huge resource prospects all over the world. Meanwhile, the development of high-sulfur gas reservoirs is also facing great challenges. In these different challenges, elemental sulfur deposition in formation is one of the main problems in gas development process (Kuo, 1972; Chesnoy and Pack, 1997; Roberts, 1997; Roberts, 2017). As the concentration of elemental sulfur in the sour gas exceeds the critical dissolved concentration during the development of sour gas reservoirs, sulfur deposition may occur in the formation. The characteristics of sulfur dissolution, like hydrocarbon dissolution in organic matter (Huang et al., 2020; Huang et al., 2021), are crucial in the analysis of elemental sulfur deposition limit and deposition amount (Smith et al., 1970; Brunner and Woll, 1980; Brunner et al., 1988). Thus, many researchers have been devoted to the study on the elemental sulfur solubility in sour gas from experiment (Kennedy and Wieland, 1960; Roof, 1971; Swift and Manning, 1976; Brunner and Woll, 
1980; Brunner et al., 1988; Davis et al., 1993; Gu et al., 1993; Sun and Chen, 2003; Zeng et al., 2005; Yang et al., 2009; Bian et al., 2010; Serin et al., 2010; Cloarec et al., 2012), thermodynamic model (Karan et al., 1998; Heidemann et al., 2001; Cézac et al., 2007; Cézac et al., 2008), semi empirical model (Chrastil, 1982; Eslamimanesh et al., 2011a; Hu et al., 2014; Guo and Wang, 2016), artificial intelligence algorithm (Mohammadi and Richon, 2008; Mehrpooya et al., 2010; Aminian, 2011; Bian et al., 2018; Fu et al., 2019; Bemani et al., 2020; Chen et al., 2020) and molecular simulation (Kadoura et al., 2013; Chen et al., 2019).

Kennedy and Wieland (Kennedy and Wieland, 1960) first measured the elemental sulfur solubility in pure $\mathrm{CH}_{4}, \mathrm{CO}_{2}, \mathrm{H}_{2} \mathrm{~S}$ and sour gas mixtures. Their results showed that the solubility of sulfur increased with increasing temperature and pressure. The $\mathrm{H}_{2} \mathrm{~S}$ solution presented the largest elemental sulfur solubility, while the $\mathrm{CH}_{4}$ solution showed the smallest solubility. However, their experimental method was questioned by roof (Roof, 1971). Subsequently, Roof (Roof, 1971) also measured the elemental sulfur solubility in $\mathrm{H}_{2} \mathrm{~S}$, and found that with the increase of temperature, the elemental sulfur solubility initially increased and then presented a decreasing trend as the solubility reached a critical point. However, the sulfur solubility experiment was limited to low temperature and low pressure conditions. Since then, Swift (Swift and Manning, 1976) and Brunner (Brunner and Woll, 1980; Brunner et al., 1988) have reported the measurement of sulfur solubility in pure $\mathrm{H}_{2} \mathrm{~S}$ under extended temperature and pressure conditions. Davis (Davis et al., 1993) extended the dissolution of sulfur in typical components to complex multicomponent sour gas, and broadened the temperature and pressure range of the experiment. Gu (Gu et al., 1993) used a set of static method equipment to determine the solubility data of sulfur in $\mathrm{CH}_{4}, \mathrm{CO}_{2}, \mathrm{H}_{2} \mathrm{~S}$ and their mixtures. Sun (Sun and Chen, 2003), Zeng (Zeng et al., 2005), Yang (Yang et al., 2009) and Bian (Bian et al., 2010) also expanded the range of the solutions and the limits of experimental conditions. Serin (Serin et al., 2010) measured the elemental sulfur solubility in pure $\mathrm{CO}_{2}$ under lower temperature and pressure conditions. Cloarec (Cloarec et al., 2012) measured the elemental sulfur solubility in pure $\mathrm{CH}_{4}$ by improving the capture device and gas expansion device, and their results were slightly different from those of Kennedy and Wieland.

The published experiments on the elemental sulfur solubility are summarized in Appendix A. With the advancement of experimental methods, the experimental pressure and temperature ranges have been extended to $0.5-138 \mathrm{MPa}$ and $303.2-563 \mathrm{~K}$, and the solutions have been extended from single-component $\mathrm{H}_{2} \mathrm{~S}, \mathrm{CO}_{2}, \mathrm{CH}_{4}$ to multi-component wellhead gas sample of the gas fields. These experimental results provide crucial data for the solubility model. However, due to the huge experimental costs, as well as the potential experimental risks from toxic gas, the experimental data of elemental sulfur solubility are far from sufficient. Especially, the experimental data of elemental sulfur solubility in sour gas mixtures from high-containing sulfur gas well in China remain limited. Also, owing to the small solubility value, the sulfur solubility is susceptible to various interferences, such as temperature, pressure, and $\mathrm{H}_{2} \mathrm{~S}$ content (Eslamimanesh et al., 2011b; Luo et al., 2012; Eslamimanesh et al., 2013). Some documented experimental work has reported inconsistent results, the elemental sulfur solubility urgently needs further verification and supplementation. The theoretic model of sulfur solubility can overcome the experimental demerits like huge cost, long period, and high risk, and thus predict the sulfur solubility conveniently. Nevertheless, the accuracy of reported theoretic models of sulfur solubility in sour gas samples from Chinese high-sulfur gas wells remains to be verified. Accordingly, this wok is aimed to supplement key sulfur solubility data in sour gas samples from Chinese high-sulfur gas well. The effects of temperature, pressure, and $\mathrm{H}_{2} \mathrm{~S}$ content are analyzed. Combined with the measured data, the accuracy of the common chrastil-type model and its extended models are further explored.

\section{EXPERIMENTAL METHODOLOGY}

\section{Principles and Apparatus}

Based on the principle of solvent dissolution, the sour gas sample is pressed into the sample reaction vessel by the piston pump, the sample reaction vessel can simulate the high temperature and high pressure of the formation. Subsequently, fully reacted and mixed sour gas sample is passed through the $\mathrm{CS}_{2}$ solution, $\mathrm{CS}_{2}$ solvent is a commonly used elemental sulfur solvent, the elemental sulfur in the sour gas sample is dissolved in $\mathrm{CS}_{2}$ solution and the content of elemental sulfur in the $\mathrm{CS}_{2}$ solution is measured with a gas chromatograph to calculate the sulfur content in the original gas sample. After that, the $\mathrm{H}_{2} \mathrm{~S}$ in the mixed gas is absorbed by the $\mathrm{NaOH}$ solution from a security perspective, and the gas flow meter can measure the volume of gas mixtures without $\mathrm{H}_{2} \mathrm{~S}$ at room temperature and pressure. The experimental apparatus is shown in Figure 1. The key parts of the apparatus are: 1) gas mixing system; 2) high temperature and high pressure resistant experimental reaction vessel; 3) gas absorption device; 4) gas chromatograph. Finally, the sulfur solubility of gas mixtures can be calculated by the following formula:

$$
c=\frac{m S}{100 V}
$$

Where $c$ is sulfur solubility, $\mathrm{g} / \mathrm{m}^{3} ; m$ is $\mathrm{CS}_{2}$ solvent quality, $\mathrm{g} ; \mathrm{S}$ is elemental sulfur content in $\mathrm{CS}_{2}$ solvent, $\% ; V$ is volume of gas mixtures, $\mathrm{m}^{3}$.

\section{Gas Sample and Determination of Elemental Sulfur Content}

The gas sample is taken from a downhole gas sample from well M1 in a sour gas field in the Sichuan Basin. The sampling depth is $3800 \mathrm{~m}$, the sampling pressure is $35 \mathrm{MPa}$, and the temperature is $98.1^{\circ} \mathrm{C}$. The temperature and pressure are restored indoors, and the opening pressure is checked. The $\mathrm{H}_{2} \mathrm{~S}$ content is determined by titration for three times. The molar contents of the three titrations are $17.982 \%, 17.891 \%$ and $17.668 \%$. Take the middle value of three titration, the $\mathrm{H}_{2} \mathrm{~S}$ content of the downhole sample 


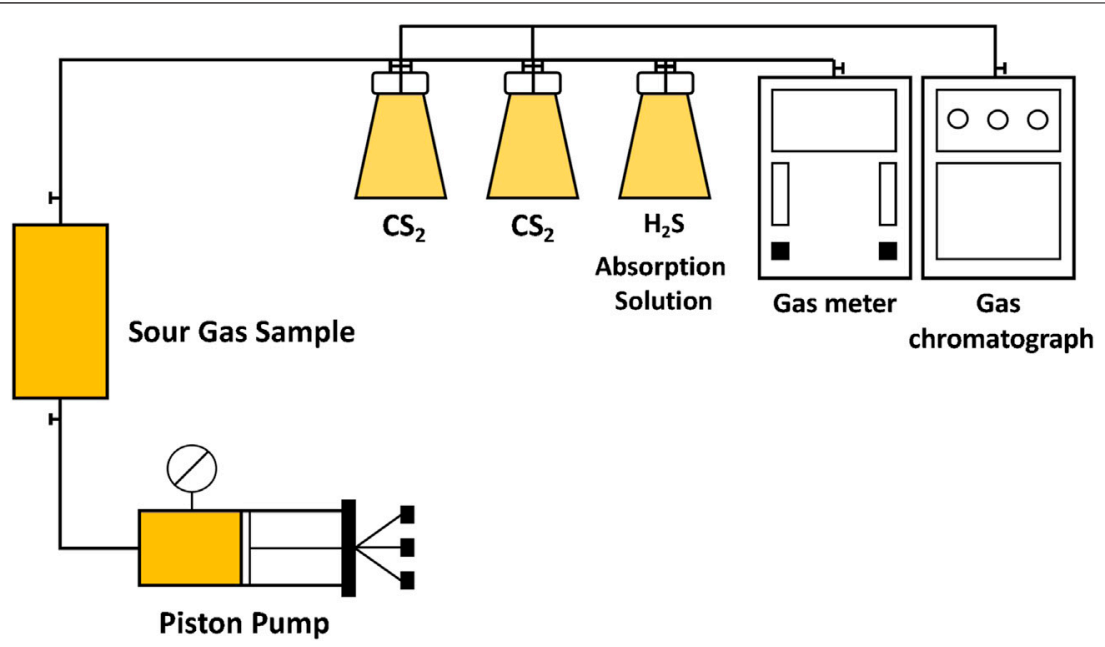

FIGURE 1 | The experimental apparatus for measuring elemental sulfur content

TABLE 1 | Solubility of elemental sulfur in well M1 by experiments and predictions.

Pressure (MPa)

of well M1 is $17.891 \%$, which is a high-sulfur content gas reservoir. The composition of the natural gas in well M1 can be obtained by gas chromatograph. The $\mathrm{CH}_{4}$ content in the gas sample is $73.418 \%$, the $\mathrm{CO}_{2}$ content is $8.66 \%$, the $\mathrm{C}_{2} \mathrm{H}_{6}$ content is $0.032 \%$, and the contents of other components are negligible.

To determine the sulfur content of a gas sample, a group of solutions with known sulfur content are used for calibration. In order to cover the measured range of elemental sulfur solubility, high-concentration standard samples were prepared. The sulfur contents are $0.005 \%, 0.01 \%, 0.03 \%$ and $0.05 \%$ respectively. The standard peak areas of different sulfur contents are used as the reference values. Then the differences between the measured peak area and the standard peak areas are used to obtain the sulfur content of the gas sample.

The elemental sulfur contents of the gas in well M1 are determined by experiments. The original elemental sulfur content of the gas sample in downhole under formation condition is $0.091 \mathrm{~g} / \mathrm{m}^{3}$, the elemental sulfur content under sampling conditions $\left(35 \mathrm{MPa}, 98.1^{\circ} \mathrm{C}\right)$ is $0.357 \mathrm{~g} / \mathrm{m}^{3}$, and the saturated sulfur content under formation conditions is $0.968 \mathrm{~g} /$ $\mathrm{m}^{3}$. Thus, the elemental sulfur in the gas sample has not reached saturation under the formation conditions and the sampling conditions.

\section{RESULTS AND DISCUSSION}

\section{Solubility of Elemental Sulfur in Well M1}

The elemental sulfur solubility experiment was carried out using gas samples from well $\mathrm{M} 1$, the solubility of elemental sulfur was measured among $40-98.9^{\circ} \mathrm{C}$ and $15-49.8 \mathrm{MPa}$. The elemental sulfur solubility was determined by taking the average of three tests for each pressure point. The errors among different measurements were checked to be smaller than $2 \%$. The experimental results are shown in Table $\mathbf{1}$ and Figure 2A. It can be seen from Figure $\mathbf{2 A}$ and Table $\mathbf{1}$ that at the same temperature, the solubility of sulfur increases with increasing pressure; and at the same pressure, the solubility of elemental sulfur increases as the temperature increases. At the formation temperature $\left(98.9^{\circ} \mathrm{C}\right)$, the solubility of elemental sulfur reaches $0.968 \mathrm{~g} / \mathrm{m}^{3}$ at $49.8 \mathrm{MPa}$ and then drops to $0.031 \mathrm{~g} / \mathrm{m}^{3}$ as the pressure decreases to $15 \mathrm{MPa}$. At the 

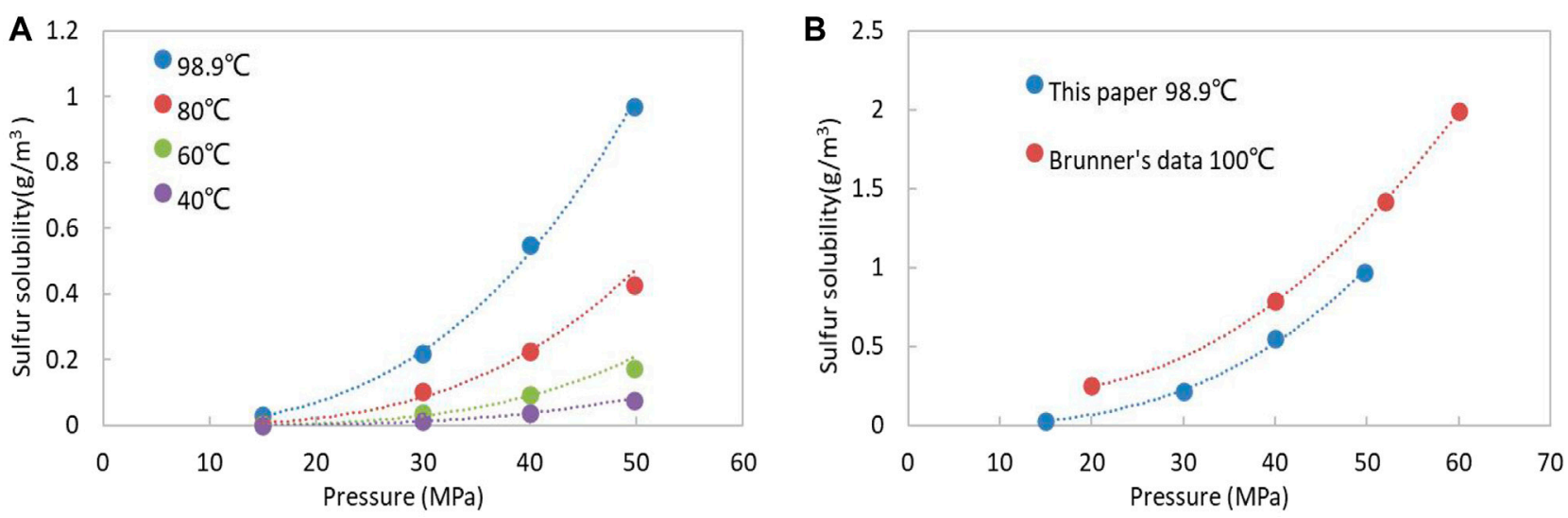

FIGURE 2 | Sulfur solubility in well M1 gas sample. (A) experimental results in this work; (B) comparison with Brunner's data at similar gas compositions. The sour gas in Brunner's data contains $20 \% \mathrm{H}_{2} \mathrm{~S}, 66 \% \mathrm{CH}_{4}, 10 \% \mathrm{CO}_{2}$, and $4 \% \mathrm{~N}_{2}$.

formation pressure $(49.8 \mathrm{MPa})$, the solubility of elemental sulfur drops to $0.076 \mathrm{~g} / \mathrm{m}^{3}$ with the temperature decreasing to $40^{\circ} \mathrm{C}$. The elemental sulfur solubility is sensitive to variations of temperature and pressure. The experimental results of sulfur solubility at $98.9^{\circ} \mathrm{C}$ are compared with Brunner's data at $100^{\circ} \mathrm{C}$ in Figure 2B (Brunner and Woll, 1980). The sour gas mixtures in Brunner's data possess similar gas compositions $\left(20 \% \mathrm{H}_{2} \mathrm{~S}, 66 \% \mathrm{CH}_{4}\right)$ with the gas samples from well M1. As seen from Figure 2B, the experimental data in this paper are basically consistent with the Brunner's data. The sulfur solubility in the literature is slightly higher than the measured results in this work, the deviations can be well attributed to the slightly higher $\mathrm{H}_{2} \mathrm{~S}$ content and temperature in Brunner's gas sample than that in this paper.

\section{Chrastil Model Fitting}

Chrastil derived solubility correlation of solids and liquids in supercritical gases base on the law of mass action (Chrastil, 1982). Chrastil model was used to study the solubility of various food additives in supercritical $\mathrm{CO}_{2}$ fluids in the early days. Subsequently, Roberts (Roberts, 1997) used the Chrastil solubility prediction model for the first time to study the solubility of elemental sulfur in sour gases containing $\mathrm{H}_{2} \mathrm{~S}$. By fitting the experimental data in the literature, the Chrastil prediction model for the solubility of elemental sulfur in sour gases was obtained. Since then, the Chrastil solubility prediction model has been widely used in the fitting of existing sulfur solubility experimental data, and the elemental sulfur solubility prediction model suitable for different temperatures and pressures and different gas components has been obtained (Eslamimanesh et al., 2011a; Hu et al., 2014; Guo and Wang, 2016). The expressions of this correlation are as follows, the detailed derivation process of this correlation and coefficients can be found in the Chrastil's paper (Chrastil, 1982):

$$
c=\rho^{k} e^{(a / T+b)}
$$

$$
\begin{gathered}
a=\frac{\Delta H}{R} \\
b=\ln \left(M_{A}+k M_{B}\right)+q-k \ln M_{B}
\end{gathered}
$$

Where $\rho$ is gas density, $\mathrm{kg} / \mathrm{m}^{3}$; $\mathrm{T}$ is temperature, $K$; $k$ is an association number, which denotes a solute $A$ associates with $k$ molecules of a gas $B$ to form one molecule of a solvato complex $\mathrm{AB}_{\mathrm{k}}$ in equilibrium with the system (Chrastil, 1982); $a$ and $b$ are constant coefficients; $\Delta H$ is the total reaction heat, $\mathrm{kJ} / \mathrm{mol} ; R$ is gas constant, $8.314 \mathrm{~J} \cdot \mathrm{mol}^{-1} \cdot \mathrm{K}^{-1} ; M_{A} 、 M_{B}$ are the molecular weights of the solute and of the gas, correspondingly; $q$ is a constant. Subsequently, Roberts obtained the constant coefficients of the expression by fitting experimental data (Roberts, 1997):

$$
c=\rho^{4} e^{(-4666 / T-4.5711)}
$$

However, Roberts's model has a limited applicability due to the temperature and pressure range and gas composition. Consequently, $\mathrm{Hu}$ proposed a segmentation fitting method according to different gas density ranges by using published data (Hu et al., 2014). Meanwhile, the three coefficients in Eq. $\mathbf{1}$ are obtained according to the above fitting method using this experiment data, The fitting process and method are detailed in Hu's article (Hu et al., 2014), the results are compared and shown in Figure 3A,B and Table 1. As seen from Figure 3A,B and Table 1, the chrastil-type model fitted in this paper has a comparatively well prediction effect, while the predicted results of the Roberts's and Hu's models deviate seriously from the experiment data, which indicates the values of coefficients $a$ and $b$ have a great influence on the predicted solubility results due to the temperature and pressure conditions and different components of the sour gas mixtures.

The association number $k$ will change with the system temperature and pressure. As the temperature increases at a constant pressure, the molecular thermal motion becomes more violent, and the association number $k$ decreases; when the temperature is a constant and the pressure increases, the molecular distance is shortened, the chance of intermolecular 

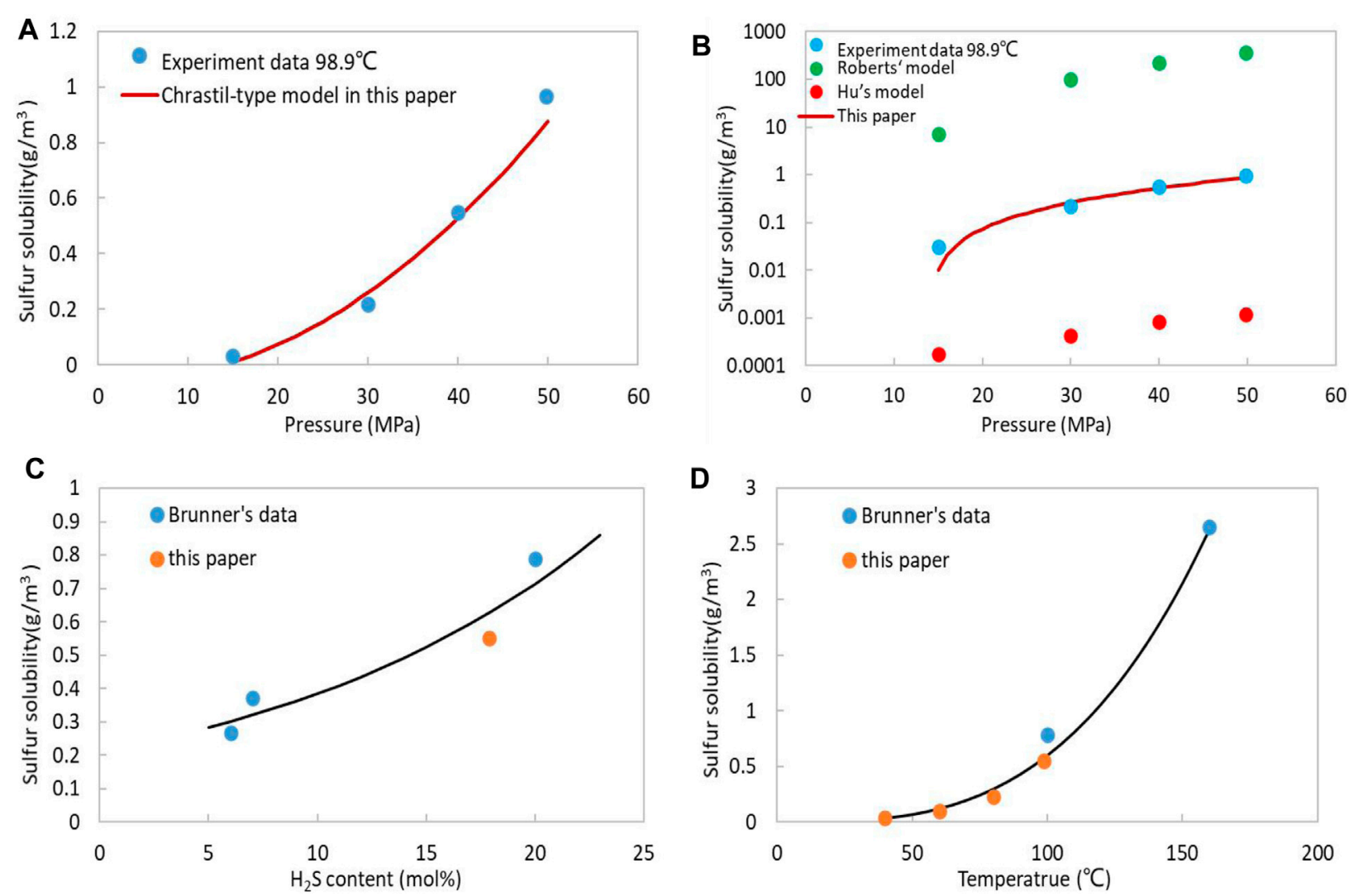

FIGURE 3 | Comparison of sulfur solubility with published data. (A) Effect of pressure at $98.9^{\circ} \mathrm{C}$; (B) Experimental sulfur solubility of this paper and published data. (C) Effect of $\mathrm{H}_{2} \mathrm{~S}$ content at $40 \mathrm{MPa}, 100^{\circ} \mathrm{C}$; (D) Effect of temperature at $40 \mathrm{MPa}$.

collisions increases, and the association number $k$ increases. $\Delta H$ will change accordingly with the association number $k$. Therefore, the practice of treating $k, a$, and $b$ as constants will inevitably lead to larger deviations. In order to improve the accuracy of the model, it is necessary to obtain the values of $k, a$, and $b$ within a specific range of temperature, pressure, and gas composition.

\section{$\mathrm{H}_{2} \mathrm{~S}$ Content and Temperature}

In order to investigate the influence of $\mathrm{H}_{2} \mathrm{~S}$ content on the solubility of elemental sulfur, the sulfur solubility data at $40 \mathrm{MPa}$ and $100^{\circ} \mathrm{C}$ in the published literature (Brunner and Woll, 1980) were compared with the measured results of sour gas mixtures from $\mathrm{M} 1$ well at $40 \mathrm{MPa}$ and $98.9^{\circ} \mathrm{C}$, as shown in Figure 3B. The results show that under the same pressure and temperature conditions, as the molar content of $\mathrm{H}_{2} \mathrm{~S}$ increases, the dissolved elemental sulfur content in the sour gas mixtures increases. The experimental results in this paper are in good agreement with the published experimental data.

Similarly, the influence of temperature on the solubility of elemental sulfur is also investigated. The sulfur solubility data of the sour gas mixtures at $40 \mathrm{MPa}$ and $100-160^{\circ} \mathrm{C}$ in the published literature (Brunner and Woll, 1980) were compared with the measured results of sour gas mixtures from M1 well at $40 \mathrm{MPa}$ and $40-98.9^{\circ} \mathrm{C}$, as shown in Figure 3C. The $\mathrm{H}_{2} \mathrm{~S}$ molar content of the sour gas mixtures in Brunner's work is $20 \%$, which is close to the $\mathrm{H}_{2} \mathrm{~S}$ content of the sour gas mixtures in this work. The results show that under the same pressure, as the temperature increases, the dissolved elemental sulfur content in the sour gas mixtures increases. The experimental results also show good consistency with Brunner's data.

\section{CONCLUSION}

In this study, the elemental sulfur solubility was measured by the static method within sour gas mixtures samples from M1 well in Sichuan Basin. The results show that the experimental data in this work show good agreement with the published results. The sulfur solubility increases with increasing pressure and temperature. At the same pressure and temperature conditions, the sulfur solubility increases as the $\mathrm{H}_{2} \mathrm{~S}$ molar content increases. The reported chrastil-type model with coefficients fitted by the measured results can well predict the sulfur solubility of gas sample from M1 well, while the presented chrastil-type formulas with documented coefficients fail to obtain reasonable prediction results. Owing to the great influence of temperature on sulfur solubility, wellbore electric heating can be utilized to prevent sulfur deposition and plugging in the wellbore, and improve sulfur recovery in the middle-late stage of sour gas reservoir development. 


\section{DATA AVAILABILITY STATEMENT}

The original contributions presented in the study are included in the article/Supplementary Material, further inquiries can be directed to the corresponding author.

\section{AUTHOR CONTRIBUTIONS}

RZ: Data creation, Formal analysis, Writing-original draft, Writingreview and editing, Funding acquisition. SG: Data creation, Visualization, Writing-review and editing. LH: Conceptualization,

\section{REFERENCES}

Aminian, Z. N. (2011). Predicting the Sulfur Precipitation Phenomena during the Production of Sour Natural Gas by Using an Artificial Neural Network. Petrol. Sci. Technol. 29, 401. doi:10.1080/10916460903394052

Bemani, A., Baghban, A., and Mohammadi, A. H. (2020). An Insight into the Modeling of Sulfur Content of Sour Gases in Supercritical Region. J. Pet. Sci. Eng. 184, 106459. doi:10.1016/j.petrol.2019.106459

Bian, X. Q., Du, Z. M., Guo, X., Tang, Y., and Yang, X. F. (2010). Measurement of the Solubility of Sulfur in Natural Gas with High $\mathrm{H}_{2}$ S Content. Nat. Gas Ind. 30, 57-58. doi:10.3787/j.issn.1000-0976.2010.12.014

Bian, X. Q., Zhang, L., Du, Z. M., Chen, J., and Zhang, J. Y. (2018). Prediction of Sulfur Solubility in Supercritical Sour Gases Using Grey Wolf OptimizerBased Support Vector Machine. J. Mol. Liq. 261, 431. doi:10.1016/ j.molliq.2018.04.070

Brunner, E., Place, M. C., Jr., and Woll, W. H. (1988). Sulfur Solubility in Sour Gas. J. Pet. Technol. 40 (12), 1587-1592. doi:10.2118/14264-pa

Brunner, E., and Woll, W. (1980). Solubility of Sulfur in Hydrogen Sulfide and Sour Gases. SPE J. 20 (5), 377-384. doi:10.2118/8778-pa

Cézac, P., Serin, J.-P., Reneaume, J.-M., Mercadier, J., and Mouton, G. (2008). Elemental sulphur Deposition in Natural Gas Transmission and Distribution Networks. J. Supercrit. Fluids 44, 115-122. doi:10.1016/j.supflu.2007.11.005

Cézac, P., Serin, J. P., Mercadier, J., and Mouton, G. (2007). Modelling Solubility of Solid sulphur in Natural Gas. Chem. Eng. J. 133 (1-3), 283-291. doi:10.1016/j.cej.2007.02.014

Chen, H., Liu, C., and Xu, X. (2019). Molecular Dynamic Simulation of Sulfur Solubility in H2S System. Int. J. Mod. Phys. B 33, 1950052. doi:10.1142/ s0217979219500528

Chen, H., Liu, C., Xu, X., and Zhang, L. (2020). A New Model for Predicting Sulfur Solubility in Sour Gases Based on Hybrid Intelligent Algorithm. Fuel 262, 116550. doi:10.1016/j.fuel.2019.116550

Chesnoy, A. B., and Pack, D. J. (1997). S8 Threatens Natural Gas Operations. Oil Gas J. 95 (17), 74-78.

Chrastil, J. (1982). Solubility of Solids and Liquids in Supercritical Gases. J. Phys. Chem. 86, 3016-3021. doi:10.1021/j100212a041

Cloarec, E., Serin, J.-P., Cézac, P., Contamine, F., Mercadier, J., Louvat, A., et al. (2012). Experimental Studies of Solubility of Elemental Sulfur in Methane at $363.15 \mathrm{~K}$ for Pressure Ranging from (4 to 25) MPa. J. Chem. Eng. Data 57, 1222-1225. doi:10.1021/je201091g

Davis, P. M., Lau, C. S., and Hyne, J. B. (1993). Data on the Solubility of Sulfur in Sour Gases. ASRL 2, 3-4.

Eslamimanesh, A., Gharagheizi, F., Mohammadi, A. H., and Richon, D. (2013). Assessment Test of Sulfur Content of Gases. Fuel Process. Techn. 110, 133-140. doi:10.1016/j.fuproc.2012.12.005

Eslamimanesh, A., Mohammadi, A. H., and Richon, D. (2011). Determination of Sulfur Content of Various Gases Using Chrastil-type Equations. Ind. Eng. Chem. Res. 50 (12), 7682-7687. doi:10.1021/ie200187v

Eslamimanesh, A., Mohammadi, A. H., and Richon, D. (2011). Thermodynamic Consistency Test for Experimental Data of Sulfur Content of Hydrogen Sulfide. Ind. Eng. Chem. Res. 50, 3555-3563. doi:10.1021/ie1017332
Project administration, Supervision, Writing-review and editing. DZ: Conceptualization, Funding acquisition, Project administration. TL: Investigation, Methodology, Writing-original draft. GZ: Formal analysis, Validation.

\section{ACKNOWLEDGMENTS}

The financial supports of National Natural Science Foundation of China (U19B6003) are acknowledged. The helpful comments and suggestions by the reviewers are greatly appreciated.

Fu, L., Hu, J., Zhang, Y., and Li, Q. (2019). Investigation on Sulfur Solubility in Sour Gas at Elevated Temperatures and Pressures with an Artificial Neural Network Algorithm. Fuel 262, 116541. doi:10.1016/j.fuel.2019.116541

Gu, M. X., Li, Q., Zhou, X. Y., Chen, Y. D., and Guo, T. M. (1993). Solubility of Solid Sulfur in Super/near-Critical $\mathrm{H}_{2} \mathrm{~S}$-Containing Sour Fluid Mixtures (I) Experimental Investigation. J. Chem. Ind. Eng. (China) 44 (3), 315-320.

Guo, X., and Wang, Q. (2016). A New Prediction Model of Elemental Sulfur Solubility in Sour Gas Mixtures. J. Nat. Gas Sci. Eng. 31, 98-107. doi:10.1016/ j.jngse.2016.02.059

Heidemann, R. A., Phoenix, A. V., Karan, K., and Behie, L. A. (2001). A Chemical Equilibrium Equation of State Model for Elemental Sulfur and Sulfur-Containing Fluids. Ind. Eng. Chem. Res. 40 (9), 2160-2167. doi:10.1021/ie000828u

Hu, J.-H., Zhao, J.-Z., Wang, L., Meng, L.-Y., and Li, Y.-M. (2014). Prediction Model of Elemental Sulfur Solubility in Sour Gas Mixtures. J. Nat. Gas Sci. Eng. 18, 31-38. doi:10.1016/j.jngse.2014.01.011

Huang, L., Khoshnood, A., and Firoozabadi, A. (2020). Swelling of Kimmeridge Kerogen by normal-alkanes, Naphthenes and Aromatics. Fuel 267, 117155. doi:10.1016/j.fuel.2020.117155

Huang, L., Zhou, W., Xu, H., Wang, L., Zou, J., and Zhou, Q. (2021). Dynamic Fluid States in Organic-Inorganic Nanocomposite: Implications for Shale Gas Recovery and CO2 Sequestration. Chem. Eng. J. 411, 128423. doi:10.1016/ j.cej.2021.128423

Kadoura, A., Salama, A., Sun, S., and Sherik, A. (2013). An NPT Monte Carlo Molecular Simulation-Based Approach to Investigate Solid-Vapor Equilibrium: Application to Elemental Sulfur-H2s System. Proced. Comput. Sci. 18, 2109-2116. doi:10.1016/j.procs.2013.05.381

Karan, K., Heidemann, R. A., and Behie, L. A. (1998). Sulfur Solubility in Sour Gas: Predictions with an Equation of State Model. Ind. Eng. Chem. Res. 37 (5), 1679-1684. doi:10.1021/ie970650k

Kennedy, H. T., and Wieland, D. R. (1960). Equilibrium in the Methane-Carbon Dioxide-Hydrogen Sulfide-Sulfur System. AIME 219, 166-169. doi:10.2118/1351-g

Kuo, C. H. (1972). On the Production of Hydrogen Sulfide-Sulfur Mixtures from Deep Formations. J. Pet. Technol. 24 (09), 1142-1146. doi:10.2118/3838-pa

Luo, Q., Tu, Z. Q., and Ji, Z. L. (2012). Influencing Factors of the Sulfur Content Measurement in High-Sulfur Natural Gas (In Chinese). Nat. Gas Ind. 32, 95-98. doi:10.3787/j.issn.1000-0976.2012.11.022

Mehrpooya, M., Mohammadi, A. H., and Richon, D. (2010). Extension of an Artificial Neural Network Algorithm for Estimating Sulfur Content of Sour Gases at Elevated Temperatures and Pressures. Ind. Eng. Chem. Res. 49 (1), 439-442. doi:10.1021/ie900399b

Mohammadi, A. H., and Richon, D. (2008). Estimating Sulfur Content of Hydrogen Sulfide at Elevated Temperatures and Pressures Using an Artificial Neural Network Algorithm. Ind. Eng. Chem. Res. 47 (21), 8499-8504. doi:10.1021/ie8004463

Roberts, B. E. (2017). Flow Impairment by Deposited Sulfur - A Review of 50 Years of Research. J. Nat. Gas Eng. 2 (1), 84-105. doi:10.7569/jnge.2017.692504

Roberts, B. E. (1997). The Effect of Sulfur Deposition on Gas Well Inflow Performance. SPE Reserv. Eng. 12 (2), 118-123. doi:10.2118/36707-pa

Roof, J. G. (1971). Solubility of Sulfur in Hydrogen Sulfide and in Carbon Disulfide at Elevated Temperature and Pressure. SPE J. Pet. Technol. 11 (3), 272-276. doi:10.2118/3264-pa 
Serin, J. P., Jay, S., Cezac, P., Contamine, F., Mercadier, J., Arrabie, C., et al. (2010). Experimental Studies of Solubility of Elemental sulphur in Supercritical Carbon Dioxide. J. Supercrit. Fluid 53 (1), 12-16. doi:10.1016/j.supflu.2010.02.010

Smith, J. J., Jensen, D., and Meyer, B. (1970). Liquid Hydrogen Sulfide in Contact with Sulfur. J. Chem. Eng. Data 15 (1), 144-146. doi:10.1021/je60044a022

Sun, C.-Y., and Chen, G.-J. (2003). Experimental and Modeling Studies on Sulfur Solubility in Sour Gas. Fluid Phase Equilibria 214, 187-195. doi:10.1016/s03783812(03)00351-0

Swift, S. C., and Manning, F. S. (1976). Sulfur-bearing Capacity of Hydrogen Sulfide Gas. SPE J. Pet. Technol. 16 (2), 57-64. doi:10.2118/5669-pa

Yang, X. F., Huang, X. P., and Zhong, B. (2009). Experimental Test and Calculation Methods of Elemental Sulfur Solubility in High Sulfur Content Gas. Nat. Gas Geosci. 20 (3), 416-419.

Zeng, P., Zhao, J. Z., and Li, Z. P. (2005). Study on the Mechanism of Sulfur Solubility in Natural Gas. J. Southwest. Pet. Inst. 27 (4), 67-69. doi:10.3863/ j.issn.1674-5086.2005.01.018

Conflict of Interest: Author RZ, SG, DZ, and TL were employed by SINOPEC.
The remaining author declares that the research was conducted in the absence of any commercial or financial relationships that could be construed as a potential conflict of interest.

Publisher's Note: All claims expressed in this article are solely those of the authors and do not necessarily represent those of their affiliated organizations, or those of the publisher, the editors and the reviewers. Any product that may be evaluated in this article, or claim that may be made by its manufacturer, is not guaranteed or endorsed by the publisher.

Copyright (c) 2021 Zhang, Gu, Huang, Zeng, Li and Zhang. This is an openaccess article distributed under the terms of the Creative Commons Attribution License (CC BY). The use, distribution or reproduction in other forums is permitted, provided the original author(s) and the copyright owner(s) are credited and that the original publication in this journal is cited, in accordance with accepted academic practice. No use, distribution or reproduction is permitted which does not comply with these terms. 


\section{APPENDIX A THE EXPERIMENTAL SUMMARY FOR DETERMINATION OF SULFUR SOLUBILITY.}

\begin{tabular}{|c|c|c|c|c|}
\hline Researcher & Time & Temperature (K) & Pressure (MPa) & Gas components \\
\hline Kennedy and Wieland, (1960) & 1960 & $338.71-394.26$ & $6.89-41.35$ & Pure $\mathrm{CH}_{4}, \mathrm{CO}_{2}, \mathrm{H}_{2} \mathrm{~S}$ and sour gas mixtures with different proportions \\
\hline 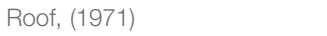 & 1971 & $316.46-383.15$ & $7-31.15$ & $\mathrm{H}_{2} \mathrm{~S}$ \\
\hline Swift and Manning, (1976) & 1976 & $394-450$ & $34.5-138$ & $\mathrm{H}_{2} \mathrm{~S}$ \\
\hline Brunner and Woll, (1980) & 1980 & $373.15-433.15$ & $10-60$ & $\mathrm{H}_{2} \mathrm{~S}$ and $\mathrm{H}_{2} \mathrm{~S}-\mathrm{CO}_{2}-\mathrm{CH}_{4}-\mathrm{N}_{2}$ mixtures \\
\hline Brunner et al. (1988) & 1988 & $398-486$ & $6.7-155$ & $\mathrm{H}_{2} \mathrm{~S}-\mathrm{CO}_{2}-\mathrm{CH}_{4}-\mathrm{N}_{2}-\mathrm{C}_{2} \mathrm{H}_{6}-\mathrm{C}_{4} \mathrm{H}_{10}$ mixtures \\
\hline Davis et al. (1993) & 1992 & $333-425$ & $5-55$ & Sour gas mixtures with different proportions \\
\hline Gu et al. (1993) & 1993 & 353.2-383.3 & $20.52-50.17$ & Pure $\mathrm{CH}_{4}, \mathrm{CO}_{2}, \mathrm{H}_{2} \mathrm{~S}$ and mixtures \\
\hline Sun and Chen, (2003) & 2003 & $303.2-363.2$ & $20-45$ & Pure $\mathrm{CH}_{4}, \mathrm{CO}_{2}, \mathrm{H}_{2} \mathrm{~S}$ and mixtures \\
\hline Zeng et al. (2005) & 2005 & $353.15-433.15$ & $10-60$ & $\mathrm{H}_{2} \mathrm{~S}-\mathrm{CO}_{2}-\mathrm{CH}_{4}-\mathrm{N}_{2}-\mathrm{C}_{2} \mathrm{H}_{6}-\mathrm{C}_{4} \mathrm{H}_{10}-\mathrm{C}_{6} \mathrm{H}_{14}$ mixtures \\
\hline Yang et al. (2009) & 2009 & 373.15 & $16-36$ & Wellhead gas sample of a gas well (mixtures) \\
\hline Bian et al. (2010) & 2010 & 336.2-396.6 & 10-55.2 & Wellhead gas sample of a gas well (mixtures) \\
\hline Serin et al. (2010) & 2010 & $333.15 / 393.15$ & $0.93-29.45$ & $\mathrm{CO}_{2}$ \\
\hline Cloarec et al. (2012) & 2012 & 363.15 & $4-25$ & $\mathrm{CH}_{4}$ \\
\hline
\end{tabular}

